\title{
PRÁTICAS DE INSERÇÃO DE TRABALHOS DE CONCLUSÃO DE CURSO NA BIBLIOTECA DIGITAL DE MONOGRAFIAS DA UFRN
}

\author{
Kimberli Vitória Valões Carvalho \\ Graduanda em Biblioteconomia \\ Curso de Biblioteconomia \\ Universidade Federal do Rio Grande do Norte \\ kimberlivitoria@yahoo.com.br \\ Raimunda Fernanda dos Santos \\ Doutoranda em Ciência da Informação \\ Programa de Pós-Graduação em Ciência da Informação \\ Universidade Federal da Paraíba \\ nandaflorania@gmail.com \\ Fernando Luiz Vechiato \\ Doutor em Ciência da Informação \\ Professor do Departamento de Ciência da Informação \\ Universidade Federal do Rio Grande do Norte

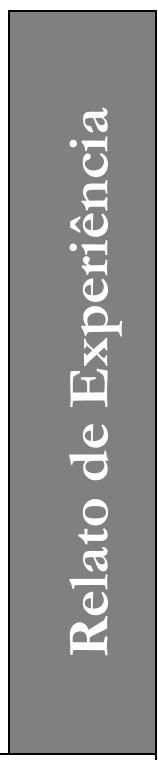

\section{Resumo}

Discorre sobre a organização e gestão da informação em repositórios institucionais de acesso aberto. Tem como objetivo relatar as práticas de arquivamento e organização dos trabalhos de conclusão de curso da coleção de Ciências Sociais Aplicadas na Biblioteca Digital de Monografias da Universidade Federal do Rio Grande do Norte. Objetiva especificamente apresentar a resolução da criação da Biblioteca Digital de Monografias dos cursos de graduação do Centro de Ciências Sociais Aplicadas dessa instituição; descrever os procedimentos realizados para a inserção das monografias no sistema; apresentar sugestões de melhorias a serem implementadas nas práticas já realizadas nesse contexto. Utiliza em seu percurso metodológico pesquisa bibliográfica, documental, descritiva e exploratória com abordagem qualitativa tendo como universo de estudo a coleção do Centro de Ciências Sociais Aplicadas disponível nesse repositório. Conclui apresentando sugestões de melhorias para a organização, gestão e divulgação das produções científicas armazenadas na Biblioteca Digital em questão, através da indicação de ações, procedimentos e diretrizes que corroborem para essa finalidade. Destaca a importância da organização da informação e gestão nos repositórios digitais e evidencia que as sugestões de melhorias apresentadas no presente relato de experiência podem ser implementadas e/ou aperfeiçoadas em Repositórios Institucionais que adotam práticas semelhantes.

\section{Palavras-chave}

Biblioteca Digital de Monografias. Universidade Federal do Rio Grande do Norte. Repositório institucional. Organização da informação - repositórios digitais institucionais.

\section{INTRODUÇÃO}

A explosão infocomunicacional reformula todo o convívio social e as maneiras pelas quais a comunicação é estabelecida, trazendo novas maneiras de comportamento perante as Tecnologias de Informação e Comunicação (TICs). Novas necessidades surgem e, diante da excessiva demanda exis- tente por informação, criam-se novos métodos e meios para a sua organização e disseminação. A partir disso, o contexto científico apresenta novas estratégias com o intuito de facilitar a criação e divulgação das produções intelectuais, fomentando a ciência em caráter mundial. Para tanto, um dos mecanismos que objetivam agregar de maneira organizada as produções científicas de uma 
instituição ou área temática são os repositórios digitais.

De acordo com o Instituto Brasileiro de Informação em Ciência e TecnologiaIBICT (2017), os repositórios digitais são bases de dados online que agregam a produção cientifica de uma instituição, podendo ter diversos formatos de arquivos. A utilização desses repositórios colabora para visibilidade dos resultados das pesquisas, contribuindo para o desenvolvimento, a disseminação e a preservação da memória científica das instituições. Nessa perspectiva, os repositórios digitais podem ser utilizados para fins institucionais ou temáticos, ou seja, focando em toda produção de uma instituição ou área temática, respectivamente.

Tendo em vista a sua importância para comunidade científica, os repositórios surgiram com o intuito de facilitar a comunicação com a sociedade, tanto para os agentes ativos em produções, como também para os usuários pesquisadores que procuram estar atualizados nos mais diversos assuntos.

Sob esse entendimento, a Biblioteca Digital de Monografias da Universidade Federal do Rio Grande do Norte (BDM/UFRN) consiste em um Repositório Institucional criado em 2011 e institucionalizado através da Resolução no 062/2015, de 05 de maio de 2015, tendo como objetivo armazenar as monografias de conclusão de curso de graduação e especialização produzidas e defendidas nos diversos Centros e Unidades Acadêmicas Especializadas dessa instituição de ensino. Destarte, esse Repositório Institucional dissemina as produções acadêmicas e busca mostrar a importância desses novos estudos desenvolvidos no âmbito da graduação/especialização como ferramentas de pesquisa introdutórias que podem subsidiar futuros aprofundamentos de estudos desenvolvidos em Dissertações/Teses. Dessa forma, é importante evidenciar neste relato de experiência o trabalho desenvolvido pelo Centro de Ciências Sociais Aplicadas da UFRN (CCSA) na $\mathrm{BDM}$ da instituição, o qual representa uma comunidade que faz parte do repositório que agrega e dissemina os trabalhos de conclusão nas coleções dos seguintes cursos: Adminis- tração, Biblioteconomia, Ciências Contábeis, Ciências Econômicas, Direito, Serviço Social e Turismo.

Nesse segmento, o artigo tem como objetivo geral relatar as práticas de arquivamento e organização dos Trabalhos de Conclusão de Curso (monografias de graduação e de especialização) na coleção do CCSA na BDM/UFRN. Sob esse viés, objetiva-se especificamente: apresentar a resolução da criação da BDM dos cursos de graduação do CCSA/UFRN; descrever os procedimentos realizados para o arquivamento e a organização das monografias no sistema; e apresentar sugestões de melhorias que possam ser implementadas nesse contexto.

Metodologicamente, este relato de experiência tem como base a pesquisa bibliográfica, documental, descritiva e exploratória com abordagem qualitativa. A partir disso, são apresentadas sugestões de práticas a serem realizadas em repositórios digitais institucionais servindo de inspiração para a criação e implementação de projetos semelhantes em outras instituições, colaborando para a perpetuação dessas novas formas de divulgação associadas à $W e b$ e à sua popularização.

Para dar continuidade a essas considerações, com vistas a apresentar posteriormente o referencial teórico e os resultados deste relato, será elencado a seguir o percurso metodológico empreendido para a sua realização, retratando os passos fundamentais para o alcance dos objetivos específicos que nortearam o estudo.

\section{PERCURSO METODOLÓGICO}

O presente relato utiliza como base a pesquisa bibliográfica, documental, descritiva e exploratória com abordagem qualitativa, uma vez que foram recuperadas e analisadas produções científicas que contribuíssem com a temática então abordada no âmbito de repositórios digitais, focando principalmente em repositórios institucionais de acesso livre, suas conceituações e tipologias. Sendo assim, para a construção do referencial teórico foram recuperadas e analisadas produções científicas como artigos científicos, anais de 
eventos técnico-científicos, teses e dissertações sobre a temática. Além disso, no intuito de obter mais informações acerca de objetivos, práticas de arquivamento e de organização das produções científicas nos Repositórios Institucionais da UFRN, em especial na BDM da instituição (coleção CCSA/UFRN), foram consultados documentos como resoluções e informações disponíveis nesse sistema com vistas a descrever os procedimentos realizados para o arquivamento e a organização das monografias na coleção do CCSA, bem como apresentar melhorias que podem ser implementadas nesse contexto.

Nesse segmento, a BDM/UFRN se constitui como universo de estudo deste relato cuja amostra delimitada foi a coleção do CCSA disponibilizada nessa ambiência. As escolhas do universo e da amostra justificam-se pela relevância que esse Repositório Institucional representa para a organização, disseminação e preservação das produções científicas e a sua disponibilização para a comunidade acadêmica. Além disso, é importante ressaltar que a coleção do CCSA se constitui na comunidade que possui maior quantidade de produções científicas arquivadas e organizadas (1369 monografias), corroborando com o reconhecimento dos trabalhos e servindo de inspiração para projetos semelhantes em outras instituições.

Desse modo, buscou-se compreender os processos que perpassam as monografias antes da sua disponibilização nesse Repositório Institucional, são eles: após a aprovação da banca avaliadora e a inserção das correções sugeridas pela mesma, o discente armazena o seu trabalho no CD; entrega à respectiva secretaria do curso; assina o termo de responsabilidade; a monografia é entregue aos responsáveis pela BDM e então é analisada mediante as autorizações para que haja a sua disponibilização no repositório em questão.

Portanto, a seguir são destacadas questões concernentes aos conceitos e às tipologias de repositórios digitais. Em especial, são descritos os aspectos históricos e os objetivos dos Repositórios Institucionais da UFRN. Posteriormente, é apresentada (detalhadamente) a descrição das práticas de ar- mazenamento e organização das produções científicas na coleção do CCSA na $\mathrm{BDM} / \mathrm{UFRN}$.

\section{REPOSITÓRIOS DIGITAIS: CON- CEITOS E TIPOLOGIAS}

Os repositórios digitais firmam-se com as novas tecnologias, tendo como princípio a explosão infocomunicacional derivada das descobertas Segunda Pós-Guerra Mundial. Nesse percurso, as TICs colaboram para o desenvolvimento de novas atividades no ambiente digital, despertando novas demandas e competências informacionais nos usuários que passam a utilizar cada vez mais frequentemente esses suportes em mudanças constantes e adaptações diante das novas necessidades.

Destarte, os aumentos da quantidade de informações então encontradas nas mais diversas redes de compartilhamento fizeram com que a comunidade científica despertasse para as novas formas de comunicação que se fizeram necessárias nesse ambiente. A velocidade do fluxo informacional é frenética, pedindo repostas quase automáticas a todos os pesquisadores, o que é beneficiado pelas Iniciativas do Acesso Aberto, colaborando para o aumento desse compartilhamento de informação científica a todo instante.

[A iniciativa de Arquivos Abertos] (OAI) estabeleceu novos critérios em relação à maneira com que as instituições e os pesquisadores lidam com o material produzido em seu âmbito, porém o estabelecimento desta filosofia está amparado por estruturas tecnológicas que permitem a publicação e consequente disseminação da informação. Essas estruturas tecnológicas são encabeçadas, principalmente, pelas ferramentas que permitem a criação de Repositórios Digitais Institucionais e Revistas eletrônicas (SANTARÉM SEGUNDO, 2010, p. 150).

Seguindo por esse viés, os repositórios digitais focam em desenvolver atividades em prol da visibilidade das produções científicas como retratado por Camargo e Vidotti (2008): 
Os repositórios digitais oferecem visibilidade para instituição, interoperabilidade de dados, controle e armazenamento da produção científica, preservação da informação a longo prazo, auto-arquivamento, acesso livre, minimização de custos de publicação, entre outras vantagens.

Em consonância de evidências, Leite (2006 apud MASSON, 2008, p. 138) conceitua os repositórios digitais como:

[...] uma consequência da aplicação da Internet e de tecnologias emergentes de informação e comunicação no contexto da comunicação científica, somada ao movimento mundial de acesso livre à informação científica, fundamentado no modelo de arquivos abertos, levando ao surgimento de modelos alternativos que provocaram mudanças paradigmáticas no processo de comunicação científica.

Nessa perspectiva, os repositórios digitais se configuram como ferramentas que agregam, preservam e divulgam as produções científicas, podendo ser categorizados de acordo com as suas tipologias e objetivos. Podendo ser de uma área do conhecimento (denominados repositórios temáticos) ou de uma instituição científica (denominados repositórios institucionais).

Café (2003 apud CAMARGO; VIDOTTI, 2008, p. 23) apresenta o conceito de repositório institucional atrelado aos repositórios temáticos:

[...] repositório institucional é a reunião de todos os repositórios temáticos hospedados em uma organização. No caso de uma universidade, cada departamento trata de uma área do conhecimento e, portanto, seu repositório temático será específico no assunto deste departamento. A união de todos os repositórios das diversas unidades de pesquisa comporá o repositório institucional, caracterizando-O como multidisciplinar.
Em vista disso, podemos enfatizar a importância dos repositórios digitais institucionais para armazenar toda produção de uma instituição, comunidade, organização e entre outras repartições que possuem o objetivo de disponibilizar informações para um grupo maior - saindo apenas de um público interno composto por funcionários, docentes e discentes para a sociedade que pode fazer uso dessas informações para enriquecer pessoalmente/profissionalmente. Tais práticas são vislumbradas no âmbito das iniciativas da UFRN, uma vez que essa instituição possui três repositórios institucionais que agregam, preservam e disseminam parte da memória acadêmica da instituição, os quais serão descritos no subtópico a seguir.

\subsection{Repositórios Institucionais da UFRN}

Diante da importância dos repositórios institucionais na preservação da memória e disseminação da informação para os mais distintos públicos dentro do invólucro acadêmico como social/cientifico, a UFRN possui três repositórios voltados a públicosalvo distintos e com diferentes tipologias de documentos disponibilizados, são eles: o Repositório Institucional (RI/UFRN); o Repositório de Informação Acessível (RIA/UFRN); e a BDM/UFRN.

$\mathrm{O}$ RI/UFRN, regido pela Resolução $\mathrm{N}^{\circ}$ 059/2010-CONSEPE, de 13 de abril de 2010, armazena a produção intelectual produzida no ambiente institucional, alocando as produções científicas de técnicos administrativos, docentes e discentes no âmbito da graduação e da pós-graduação. Sendo assim, disponibiliza os seguintes documentos: artigos publicados em periódicos, trabalhos completos publicados em eventos, dissertações e teses, livros eletrônicos e capítulos de livros. Nessa perspectiva, o RI/UFRN tem o intuito de potencializar o desenvolvimento de pesquisas, proporcionar maior visibilidade da produção institucional, ampliando sua importância em nível nacional/mundial.

O RIA/UFRN, por sua vez, é regido pela Resolução $N^{\circ}$ 054/2014-CONSEPE, de 11 de março de 2014, assegurado pelas leis e decretos instituídos na Política Nacio- 
nal de Educação Especial e Direito das Pessoas com Deficiência da Organização das Nações Unidas (ONU), conforme descrito na resolução. A proposta desse repositório digital é o armazenamento de materiais acessíveis para pessoas com necessidades especiais, veiculando a digitalização e adaptação desses arquivos para formatos acessíveis, assim como a preservação de todo esse material para atender precisamente ao público. Através disso, o material disponível no RIA/UFRN pode auxiliar os discentes, aprimorando o processo de ensinoaprendizagem com o intuito dos mesmos não serem prejudicados no ambiente acadêmico. No entanto, a maior parte dos materiais informacionais disponíveis nesse repositório não está disponível para acesso público para não infligir a Lei de Direitos Autorais, voltando-se restritamente para discentes que são apoiados pela Comissão Permanente de Apoio a Estudantes com Necessidades Educacionais Especiais (CAENE) criada em 2010. Assim, a CAENE tem a finalidade de “apoiar, orientar e acompanhar a política de inclusão de estudantes com necessidades educacionais especiais no âmbito desta universidade". Os discentes também recebem apoio do Laboratório de Acessibilidade, sendo o responsável pela produção e adaptação do material então disponibilizado, servindo gratuitamente aos alunos apoiados por essa Comissão, tendo serviços personalizados de acordo com as necessidades relatadas, podendo então usufruir das tecnologias assistivas oferecidas.

Por fim, a BDM/UFRN, universo deste relato de experiência, é responsável por armazenar os trabalhos de conclusão de cursos de graduação e especialização oferecidos pela Universidade. Sendo mais bem detalhada na subseção posterior, onde é descrita a sua trajetória de implementação.

\subsubsection{Biblioteca Digital de Monografias da UFRN (BDM/UFRN)}

A BDM/UFRN tem como principal finalidade o armazenamento de monografias no nível de graduação e especialização ambientadas na instituição. Assim, as monografi- as se caracterizam como parte de um conhecimento que se lapida no primeiro contato do discente com a pesquisa, servindo muitas vezes de base para um estudo mais aprofundado e então desenvolvido na pósgraduação. Nesse segmento, a BDM/UFRN surgiu em 2011 através de uma parceria do Departamento de Ciência da Informação (DECIN/CCSA) e da Biblioteca Central Zila Mamede (BCZM).

O projeto inicial tinha como intuito a disponibilização das monografias apenas do Curso de Biblioteconomia, podendo disseminar os trabalhos então finalizados no ambiente acadêmico para toda comunidade. Porém, em 2011 o projeto expandiu contemplando todos os cursos de graduação existentes no CCSA, sendo obrigatória a disponibilização desse material, visto sua importância para a comunidade - servindo de retorno intelectual ao investimento então fornecido pela instituição.

No entanto, apenas no ano de 2015, através da Resolução $\mathrm{N}^{\circ}$ 062/2015CONSEPE, a BDM passou a comportar todas as monografias dos cursos ativos na UFRN, tendo como unidade gestora a BCZM. O seu objetivo frisa-se em organizar, preservar e armazenar como descrito na Resolução, podendo então corroborar com o desenvolvimento da ciência no Brasil.

O Repositório encontra-se hospedado no Software Dspace, o qual é responsável por oferecer toda estrutura, sendo de fácil customização e atendendo bem às demandas então necessárias para o bom funcionamento do sistema. A BDM possui o padrão de metadados no formato Dublin Core, onde ocorre a descrição do arquivo de maneira coerente aos campos disponibilizados. Atualmente, o depósito dos trabalhos de conclusão de curso é realizado por alguns centros e departamentos através do autoarquivamento onde o usuário faz sua inscrição previamente, sendo autorizado a efetuar o depósito do seu trabalho mediante a confirmação dos dados realizada pela BCZM.

A partir disso, o discente pode escolher a coleção onde será inserida a sua monografia e preencher os campos do trabalho de acordo com o documento final, após as 
correções da banca examinadora. Assim, o usuário autor tem total autonomia na descrição temática de sua produção científica atribuindo os descritores julgados como coerentes para representar o conteúdo de seus documentos no metadado assunto deste repositório digital - cabendo posteriormente ao profissional da informação responsável pela Biblioteca Digital a análise e correção de tais termos para fins de disponibilização desse material.

$\mathrm{Na}$ página principal da BDM/UFRN, junto aos documentos históricos e institucionais, podem ser encontrados os tutoriais disponibilizados pela equipe técnica, ensinando através de passo-a-passo todas as instruções necessárias para que a submissão realizada pelos usuários seja a mais coerente possível, respeitando todas as áreas e finalidades dos campos, possuindo exemplos de utilização.

Para dar segmento a essas considerações, a seguir são apresentados os resultados deste relato. É importante ressaltar que as informações apresentadas são provenientes das experiências, da prática profissional e das pesquisas realizadas na BDM/UFRN, bem como das experiências dos autores deste trabalho enquanto usuários da BDM/UFRN.

\section{PRÁTICAS DE INSERÇÃO DE TRABALHOS DE CONCLUSÃO DE CURSO NA BDM/UFRN}

As práticas de inserção de trabalhos de conclusão de curso da coleção do CCSA/UFRN na BDM, diferentemente de outros centros e departamentos da instituição, não ocorrem por meio autoarquivamento. Tal prática está descrita na Resolução ${ }^{\circ}$ 01/2012-/CONSEC/CCSA da seguinte forma:

Compete ao Departamento de Biblioteconomia, atualmente denominado de Ciência da Informação, coordenar a implementação da $\mathrm{BDM} / \mathrm{CCSA}$, utilizando-se do software livre para disponibilização do material e o protocolo de metadados padrão; compete às coordena- ções de curso coletar os trabalhos de conclusão de curso dos discentes, no formato digital em arquivo único, gravado em $\mathrm{CD}$ ou DVD, identificado com nome do curso, título e ano da monografia, nome do professor orientador e aluno, acompanhado do termo de autorização devidamente preenchido e assinado por ambos; compete aos professores orientadores verificar, junto aos seus orientandos, se a versão que será entregue à coordenação é a versão final do trabalho, assinando o termo de autorização; A BCZM será responsável pelo apoio e suporte técnico na manutenção e customização do software utilizado para criação da Biblioteca; os cursos de graduação do CCSA deverão adotar para as monografias as padronizações condizentes empregadas nacional e/ou internacionalmente.

Assim, as coordenações dos cursos do CCSA são responsáveis por receber, coletando todas as monografias entregues em CD junto a um Termo de Autorização respondido a mão pelo discente, onde ele (na qualidade de autor do trabalho) preenche os campos que descrevem o seu trabalho e colaboram para inserção dos dados no sistema. $\mathrm{Na}$ oportunidade, é indicado: Nome completo, número de matrícula do discente (autor do trabalho), componentes da banca examinadora, orientador, curso de graduação, e-mail, palavras-chave do resumo de sua produção intelectual, assim como assinatura do autor e orientador consentindo (ou não) a publicação (veiculação) do trabalho em questão - mediante autorização que pode ser total, parcial ou não autorizado.

Depois de recolhido esse material, o secretário encaminha para a BDM/UFRN, onde ocorre a separação das monografias a partir da autorização concedida pelo discentes. Após essa separação, é montado um documento com a lista de metadados detalhando as informações de cada campo solicitado pelo sistema, facilitando e otimizando o cadastro a ser realizado posteriormente no repositório. A validação ocorre após uma 
última inspeção feita pelo responsável da $\mathrm{BDM}$, o qual deve verificar a ocorrência de erros nas descrições contidas no documento e suas respectivas correções. Após essa revisão, ocorre a validação para publicação, sendo disponibilizada imediatamente no reposi- tório. Em situações divergentes, em que o discente não assinala corretamente os campos identificados e/ou alguma informação importante, o mesmo será contatado pelos responsáveis da BDM/UFRN.

Figura 1 - Depósito na BDM/UFRN

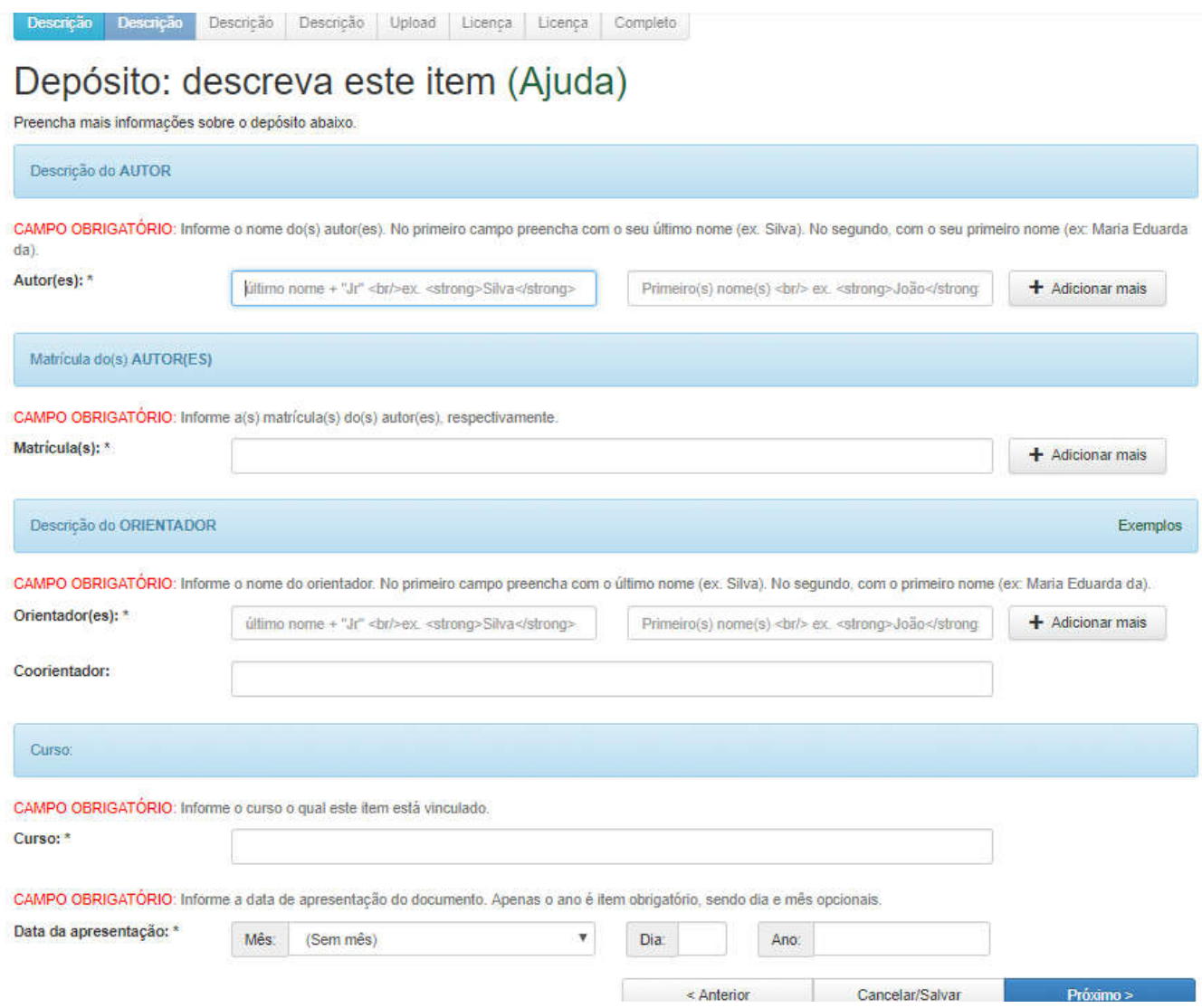

Fonte: Elaboração própria (2017).

Como elucidado anteriormente, é possível observar de que maneira ocorre a descrição dos materiais então submetidos na $\mathrm{BDM} / \mathrm{UFRN}$. O discente tem acesso à área de submissão no momento em que é dada a autorização pelo setor responsável dos repositórios da instituição. As Figuras 1 e 2 ilustram essa parte. Assim, o usuário preenche os campos em branco conforme detalhado em seu trabalho de conclusão de curso. Mediante o avanço no preenchimento de cada campo, o Dspace libera novas abas de submissão, percorrendo todo passo a passo. Em seguida, o usuário-autor faz a submissão do trabalho completo, concedendo a publicação junto à UFRN. Em outra aba, é possível o usuário-autor utilizar o Creative Commons, escolhendo uma licença personalizada conforme o tipo de disponibilização desejada. 
Figura 2 - Depósito na BDM/UFRN

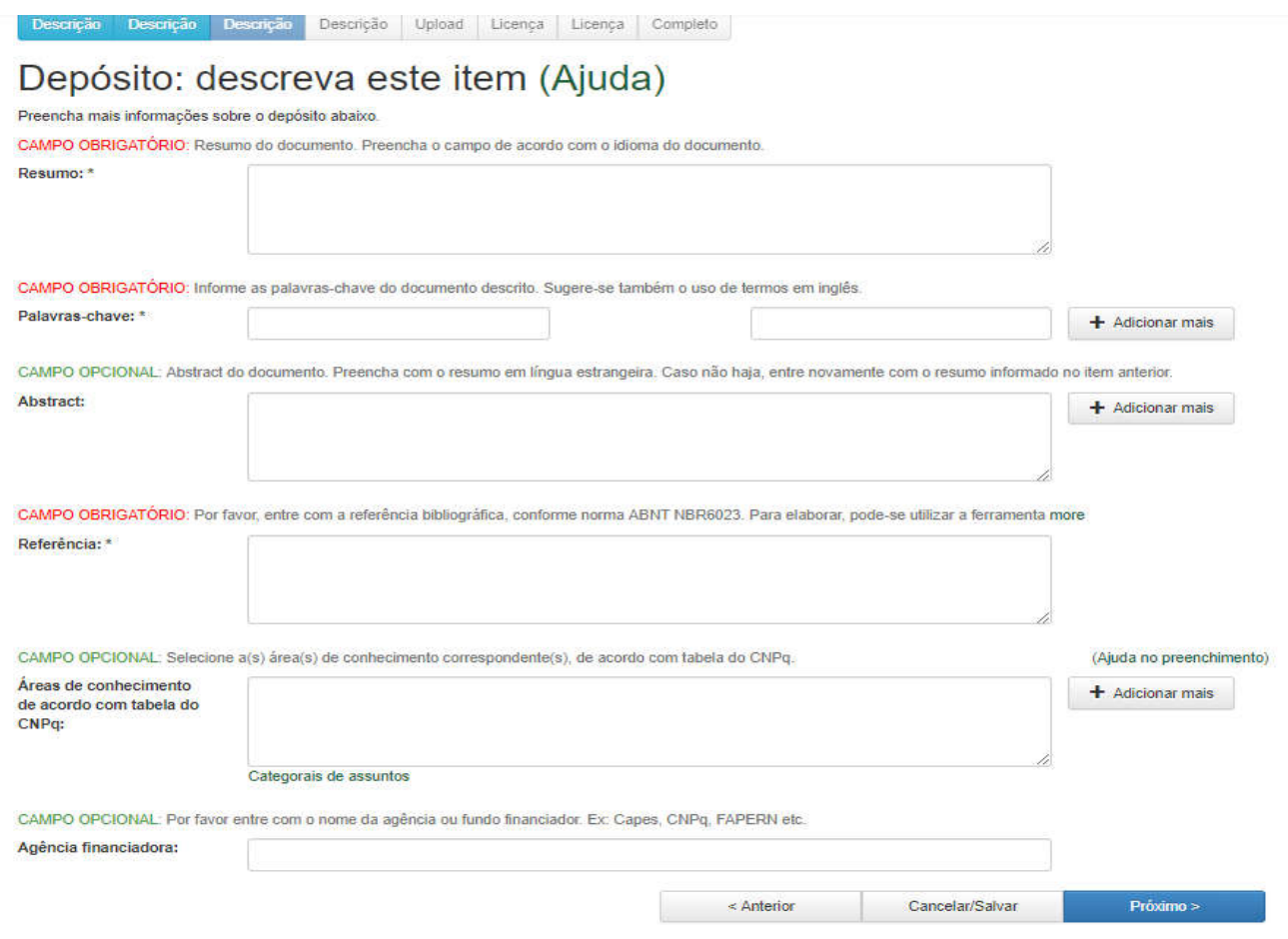

Fonte: Elaboração própria (2017).

O processo de autoarquivamento ainda não é realizado no CCSA, mas em outros departamentos da UFRN já é possível encontrar tal prática. Pensando nisso, toda customização do sistema é autoexplicativa, onde possui vários lembretes e dando exemplos de como os campos devem ser preenchidos, pois cada metadado condiciona as estratégias de busca e de recuperação da informação.

No âmbito da UFRN, existem vários profissionais responsáveis pela inserção das monografias no repositório, o que constitui como um trabalho colaborativo. No entanto, a BCZM é responsável pelo apoio e suporte técnico, atuando junto ao setor de repositórios digitais, hospedado pela Superintendência de Informática (SINFO/UFRN).

\section{SUGESTÕES DE MELHORIAS A SEREM IMPLEMENTADAS}

Como destacado anteriormente, podemos visualizar que o trabalho praticado na BDM/CCSA é colaborativo, dependendo da união das secretarias dos departamentos para com o repositório, visando por um bem comum, que vai muito além da disponibilização das monografias, uma vez que torna acessível a informação contida em cada arquivo produzido pelos discentes.

A comunicação é parte principal na composição de um bom trabalho. É importante que as secretarias possam trabalhar conjuntamente com o repositório, separando o material devidamente e o organizando. Sendo assim, é relevante estar atento, no momento em que o discente efetuar a entrega do material, se os campos do formulário foram preenchidos corretamente, pois pode ser que o discente se esqueça de assinalar a devida autorização ou deixando algum campo importante em branco/incompleto.

O discente é responsável pelo preenchimento dos campos que descrevem a sua produção intelectual a ser depositada na coleção do CCSA na BDM/UFRN. As informações disponibilizadas em tais campos são coletadas para fins de preenchimento de metadados descritivos e 
temáticos no repositório institucional pelos gestores da BDM/UFRN, objetivando a representação, a recuperação, o acesso e o uso de cada produção científica. Sendo assim, a descrição realizada pelo discente autor através do formulário a ser entregue para esses gestores contempla elementos de representação descritiva e temática do seu documento que podem ocasionar implicações positivas ou negativas no processo de recuperação do seu trabalho no repositório institucional. Destarte, verifica-se a necessidade de conscientizá-los acerca da importância do preenchimento correto e da correção de tais campos, bem como a necessidade de elaboração de diretrizes e, consequentemente, de um manual que possam orientar tais práticas a serem realizadas tanto pelos autores quanto pelos gestores do repositório institucional.

Ainda que a política de autoarquivamento possa ser adotada por outros departamentos da instituição, verifica-se que também existe a necessidade $\mathrm{da}$ interferência de profissionais $\mathrm{da}$ informação no processo de validação e de correção dos metadados apresentados pelos usuários, principalmente na escolha das palavras-chave representativas dos conteúdos dos seus documentos. Os usuários podem desconhecer o seu real significado em uma plataforma de busca. Portanto, observa-se também a necessidade de criação de um programa de educação de usuários a ser implementado pelos profissionais da informação que trabalham no RI/UFRN mediante o uso de suas competências e habilidades.

Para que ocorra exxito no recebimento ou publicação das monografias, se faz necessário o empenho, por parte dos gestores da BDM/UFRN, na verificação desse material, julgando importante saber se as monografias também estão dentro das padronizações exigidas e descritas pela resolução.

Apesar de muito conhecidas no âmbito acadêmico, as normas da Associação Brasileira de Normas Técnicas (ABNT), ainda não são aplicadas em sua integridade nos trabalhos de conclusão de curso armazenados no RI/UFRN, o que pode comprometer na qualidade de sua apresentação e visualização pela comunidade acadêmica. Diante disso, se faz necessário que a Biblioteca Central e as unidades setoriais da instituição, em parceria com os discentes e docentes, trabalhem de forma mais enfática na orientação para o desenvolvimento de trabalhos científicos de acordo com as normas. Sendo assim, como sugestão, o trabalho apresentado pelo aluno só pode ser depositado no repositório em questão, caso esteja efetivamente adequado às normas de padronização de trabalhos acadêmicos/científicos.

Assim como toda biblioteca que possui acervo físico, as bibliotecas digitais precisam ter um manual que descreva as diretrizes de práticas para a sua organização interna e externa. Para o administrador, é de suma importância que os colaboradores saibam quais são os direitos e deveres até então trabalhados na organização do acervo digital do RI. É importante que as regras de publicação sejam claras para que não ocorra desgaste das partes envolvidas, não sendo necessária a retomada do material repetidas vezes por falta de informações.

A organização interna é importante para uma biblioteca digital saber como estão as publicações por cursos, quais os frequentes erros que ocorrem e saber se realmente todos os discentes formados naquele período tiveram as suas monografias disponibilizadas ou responderam devidamente ao Termo deixando sua autorização, sendo a favor ou contra a publicação. Esse tipo de organização também pode esclarecer e apresentar informações acerca do andamento do curso, bem como evidenciar a quantidade de formandos e a formulação de indicadores para as tomadas de decisões.

A utilização dos formatos de texto como o PDF é muito recorrente em várias bibliotecas e repositórios digitais, no entanto, expandir esse horizonte para outros formatos poderia auxiliar a leitura do arquivo. Por conseguinte, formatos como o EPUB podem contribuir com o acesso e a utilização dos materiais informacionais 
disponibilizados no repositório. Documentos nesse formato conseguem adaptar-se ao suporte pelo qual está sendo acessado e com a crescente usabilidade dos smartphones como ferramentas de estudo pelos usuários. Além do mais, a preocupação com acessibilidade deve ser primordial, visto o público de pessoas com deficiência presentes nas universidades, $\mathrm{O}$ uso de formatos como o PDF/A auxiliaria na integração desse público ao uso ininterrupto dos arquivos.

A promoção e divulgação é algo imprescindível para o reconhecimento da importância da BDM/UFRN junto à comunidade acadêmica da instituição e da sociedade em geral. Um repositório digital precisa de público para que se mantenha ativo, propagando seu real objetivo de disseminar a informação. Não obstante, a falta de conhecimento do público a qual se destina essa atividade e até mesmo partes integrantes é, no mínimo, desinteressante. Nesse sentido, observa-se a necessidade de criação de um plano de marketing voltado para a BDM/UFRN com vistas a propor melhorias para a sua gestão e promoção.

Em vista disso, a implementação das políticas, manuais e diretrizes de arquivamento, gestão e organização da informação nesse cenário se faz necessário, para que a BDM/UFRN cumpra efetivamente o objetivo de preservar, organizar e disseminar parte da memória acadêmica da instituição.

Quadro 1 - Síntese das sugestões de Melhorias para a BDM/UFRN

\begin{tabular}{|c|}
\hline Sugestões de Melhorias \\
\hline $\begin{array}{l}\text { - Criação de um Programa de Comunicação entre Departamentos que alimentam as comunidades e cole- } \\
\text { ções da BDM/UFRN. }\end{array}$ \\
\hline $\begin{array}{l}\text { - Realização de análise prévia da padronização das monografias como etapa que antecede o seu arquiva- } \\
\text { mento pelo gestor da BDM/UFRN. }\end{array}$ \\
\hline $\begin{array}{l}\text { - Elaboração de um Programa de Educação de Usuários para preenchimento de formulários/metadados } \\
\text { e/ou realização de autoarquivamento de produções científicas. }\end{array}$ \\
\hline $\begin{array}{l}\text { - Criação de uma política que oriente as práticas de representação descritiva e temática dos documentos, } \\
\text { bem como as suas respectivas correções no repositório institucional em questão. }\end{array}$ \\
\hline $\begin{array}{l}\text { - Elaboração de um manual com diretrizes que auxiliem as práticas de gestão interna e externa da } \\
\text { BDM/UFRN. }\end{array}$ \\
\hline $\begin{array}{l}\text { - Inclusão de novos formatos de arquivo que visem a acessibilidade das produções científicas como E-pub } \\
\text { e PDF/A. }\end{array}$ \\
\hline $\begin{array}{l}\text { - Criação e implementação de um plano de Marketing voltado para a inclusão de melhorias, bem como } \\
\text { para a promoção e comunicação do Repositório Institucional em questão. }\end{array}$ \\
\hline
\end{tabular}

Portanto, as sugestões supracitadas são provenientes das experiências, da prática profissional e das pesquisas realizadas pelos autores neste repositório institucional, bem como pelas suas experiências enquanto usuários da BDM/UFRN. Acredita-se, nesse sentido, que tais sugestões podem contribuir de forma significativa para a gestão, organização, preservação, recuperação, acesso e uso de todas as produções científicas disponíveis, tanto na coleção do CCSA/UFRN quanto nas demais coleções presentes nesse Repositório Institucional.

\section{CONSIDERAÇÕES FINAIS}

O meio digital está cada vez mais em expansão, tendo essa noção do ilimitado onde tudo pode ser facilmente recuperado com ajuda dos buscadores e das bases de dados. De certa forma, os repositórios acompanham essa nova leva tecnológica surgida por tamanha necessidade de informação para manter-se atualizado mediante a quantidade de dados que são produzidos diariamente. As pesquisas precisam cada vez mais se tornar pioneiras, para isso, é impor- 
tante que os pesquisadores estejam sempre atentos às novidades ao redor do mundo.

Em linhas gerais, este relato de experiência pode ser concluído priorizando a dialética de como as bibliotecas digitais/repositórios digitais estão se modernizando conforme as novas necessidades informacionais e tecnologias aplicadas na sociedade. Para tanto, as instituições mantenedoras precisam despertar para as diferentes formas com que esse novo saber cientifico está se propagando e desenvolver projetos que colaborem para a gestão e organização das produções científicas armazenadas em Repositórios Institucionais. Cabe aos profissionais envolvidos na gestão dos Repositó- rios Institucionais reconhecerem as demandas necessárias para lidar com as novas ferramentas então incorporadas e desenvolver novas competências e habilidades para administrá-las corretamente, ressaltando assim a importância do profissional da informação em atuar efetivamente na Organização da Informação e gestão de Repositórios Institucionais, em especial na BDM/UFRN.

Portanto, acredita-se que as sugestões de melhorias apresentadas neste relato de experiência também possam ser implementadas ou aperfeiçoadas em Repositórios Institucionais que adotam práticas semelhantes à BDM/UFRN.

\title{
INSERTING PRACTICES OF COURSE CONCLUSION WORKS IN THE UFRN MONOGRAPHS DIGITAL LIBRARY
}

\begin{abstract}
Discusses the organization and management of information in open access institutional repositories. It aims to report on the archiving and organization practices of the course completion works from the collection of Applied Social Sciences in the Digital Library of Monographs of the Federal University of Rio Grande do Norte (Brazil). Specifically aims to present the resolution of the creation of the Digital Library of Monographs of the undergraduate courses of the Center of Applied Social Sciences of this institution; describe the procedures performed for the insertion of the monographs in the system; present suggestions for improvements to be implemented in the practices already carried out in this context. It uses in its methodological research bibliographic, documentary, descriptive and exploratory research with qualitative approach having as study universe the collection of the Center of Applied Social Sciences available in this repository. Concludes by presenting suggestions for improvements to the organization, management and dissemination of the scientific productions stored in the Digital Library in question, indicating the actions, procedures and guidelines that corroborate for this purpose. It highlights the importance of the organization of Information and management in digital repositories and evidences that the suggestions for improvements presented in this report of experience can be implemented and / or improved in institutional repositories that adopt similar practices.
\end{abstract}

Keywords

Digital Library of Monographs. Federal University of Rio Grande do Norte. Institutional repository. Organization of information - institutional digital repositories.

Artigo recebido em 02/06/2018 e aceito para publicação em 27/06/2018

\section{REFERÊNCIAS}

CAMARGO, L. S. A.; VIDOTTI, S. A. B. G. Uma estratégia de avaliação em repositórios digitais. In: SEMINÁRIO NACIONAL DE BIBLIOTECAS UNIVERSITÁRIAS (SNBU), 26., 2008, São Paulo. Anais... São Paulo: s.n, 2008. v. 15, p. 1-6. Disponível em:

$<$ https://s3.amazonaws.com/academia.edu. docu-
ments/28541424/3560.pdf?AWSAccessKey Id=AKIAIWOWYYGZ2Y53UL3A\&Expir es $=1508173262 \&$ Signature $=i i M H i Q h c 0 / x v s$ $\mathrm{iVnFgYu4rAFbu} 4=\&$ response-contentdisposition =inline; filename=Uma_estrategia_de_avaliacao_em_repo sitor.pdf>. Acesso em: 16 out. 2017.

INSTITUTO BRASILEIRO DE INFORMAÇÃO EM CIÊNCIA E TECNOLOGIA (IBICT). Sobre repositórios digitais. 
201-. Disponível em:

$<$ http://www.ibict.br/informacao-para-

ciencia-tecnologia-e-inovacao / repositorios-

digitais >. Acesso em: 29 ago. 2017.

MASSON, S. M. Os repositórios digitais no âmbito da sociedade informacional. PRIS-

MA.COM, [S. 1.], v.1, n.7, p.105-152. Dis-

ponível em: <

http://revistas.ua.pt/index.php/prismacom /article/view/679>. Acesso em: 15 out. 2017.

SANTÁREM SEGUNDO, J. E. Representação iterativa: um modelo para repositórios digitais. 2010. 225 f. Tese (Doutorado) Curso de Ciência da Informação, Faculdade de Filosofia e Ciências, Campus de Marília Sp, Marília, 2010. Disponível em:

$<$ https://www.marilia.unesp.br/Home/Pos

Gradua-

cao/CienciadaInformacao/Dissertacoes/san taremsegundo_je_do_mar.pdf $>$. Acesso em: 03 set. 2017.

CONSELHO DE ENSINO, PESQUISA E EXTENSÃO. Resolução n $^{\circ}$ 054/2014CONSEPE, 11 de março de 2014. Natal, RN: UFRN, 2014. Estabelece normas sobre a política institucional de informação do Repositório de Informação Acessível (RIA) da Universidade Federal do Rio Grande do
Norte (UFRN). Disponível em:

$<$ https://ria.ufrn.br/jspui/documentos/res olucao_592010_consepe_riaufrn.pdf $>$.

Acesso em: 03 set. 2017.

Resolução $\mathrm{n}^{\circ}$ 062/2015-

CONSEPE, de 05 de maio de 2015. Estabelece normas sobre a Política Institucional de Informação na Universidade Federal do Rio Grande do Norte UFRN no que se refere a sua Biblioteca Digital de Monografias e outros produtos de Trabalhos de Conclusão de Cursos de Graduação e Especialização (BDM). Natal, RN: UFRN, 2015. Disponível em:

$<$ http://monografias.ufrn.br:8080/jspui/do cumen-

tos/Politica_de_informacao_da_BDM_UFR N.pdf>. Acesso em: 03 set. 2017.

\section{. Resolução ${ }^{\circ}$ 059/2010-}

CONSEPE, de 13 de abril de 2010. Estabelece normas sobre a Política Institucional de Informação Técnico Científica na Universidade Federal do Rio Grande do Norte UFRN no que se refere ao seu Repositório Institucional (RI). Natal, RN: UFRN, 2010. Disponível em:

$<$ http://repositorio.ufrn.br:8080/jspui/doc umen-

tos/resolucao_592010_consepe_riufrn.pdf> . Acesso em: 03 set. 2017. 